Full Length Article

\title{
Prediction of nano/micro aluminum particles ignition in oxygen atmosphere
}

\author{
Xiangrui Zou ${ }^{\mathrm{a}}$, Ningfei Wang ${ }^{\mathrm{a}}$, Lijuan Liao ${ }^{\mathrm{b}, *}$, Qingzhao Chu ${ }^{\mathrm{a}}$, Baolu Shi ${ }^{\mathrm{a}, *}$ \\ ${ }^{a}$ School of Aerospace Engineering, Beijing Institute of Technology, No. 5 Zhongguancun South Street, Haidian, Beijing 100081, China \\ ${ }^{\mathrm{b}}$ Key Laboratory for Mechanics in Fluid Solid Coupling Systems, Institute of Mechanics, Chinese Academy of Sciences, No. 15 BeiSihuan West Road, Beijing 100190, China
}

A R T I C L E I N F O

\section{Keywords:}

Nano/micro aluminum particles

Ignition temperature

Ignition delay time

Heat transfer

Oxidation

\begin{abstract}
A B S T R A C T
Ignition prediction of aluminum particle is of great significance for a variety of propulsion and power systems to achieve optimal energy release within a limited residence time. In this study a heat transfer model employing temperature dependent coefficients was developed and validated to describe the heat exchange between quiescent/flow gas and aluminum particles from nano- to micro-size, covering the free-molecular to continuum regimes. By coupling heat transfer and aluminum oxidation, a theoretical model has been proposed to accurately capture ignition properties of both aluminum nanoparticle and microparticle (ANP and AMP) burning in hot oxygen atmosphere. Two formulas were obtained to predict the ignition temperature and ignition delay time for nano/micro particles, which show good agreements with experimental results, providing a convenient and accurate method for practical application. A parametric study illustrates that AMP ignition is affected by bulk flow velocity, radiation and oxygen concentration, particularly for AMP over $100 \mu \mathrm{m}$ in diameter; in contrast, ANP is more sensitive to alumina thickness which generally raises both ignition temperature and ignition delay time. The present study not only deepens the fundamental understanding of aluminum combustion but also provides a guideline for prompting ignition.
\end{abstract}

\section{Introduction}

Aluminum powder has been widely used in a variety of applications owing to its evident merits such as high energy density, low cost and abundance on the earth $[1,2]$. As the energetic additives, aluminum microparticles (AMPs) are used in propellants and explosives etc. [3,4]. Aluminum nanoparticles (ANPs), with very high specific surface area that yields high reactivity and low ignition temperature, have received keen interests [5]. It has been recognized as a potential energy carrier in transport or power systems to reduce the pollutant emissions $\left(\mathrm{NO}_{\mathrm{x}}\right.$, $\mathrm{CO}_{2}$ ), for example, in internal combustion engine (ICE) $[6,7]$ and gas turbine engine [8].

Covered by the passive alumina shell, the ignition of AMP and ANP becomes difficult, resulting in subsequent challenges including incomplete burning and aggregation etc. [9,10]. Such defects significantly influence the combustion efficiency, restricting the vast applications of aluminum powder. Meanwhile, the ignition characteristics vary significantly with particle size, oxidizer property and bulk gas motion. To meet various practical applications correlated with given temperatures and residence times, the ignition strategies for both AMP and ANP should be well designed on the basis of insightful understanding on ignition mechanism.
Over several decades' study on the AMP ignition, plenty of ignition modes have been proposed. In the experiment of AMP burning in an atmospheric post flame, Friedman and Macek [11] pointed out that AMP can be ignited as the environmental gas temperature exceeded $2210-2360 \mathrm{~K}$, and such temperature was insensitive to the particle size; in addition, the ignition delay time $\left(t_{\mathrm{ig}}\right)$ was inversely proportion to square of particle diameter $\left(D_{\mathrm{p}}\right)$. While Gurevich et al. [12] argued that the ignition temperature $\left(T_{\mathrm{ig}}\right)$ was lower than the melting temperature of alumina; and $T_{\mathrm{ig}}$ was strongly dependent on $D_{\mathrm{p}}$ in contrast to Friedman's conclusion. With a series of measurements, Merzhanov et al. $[13,14]$ provided valuable dataset for the chemical kinetics of aluminum oxidation within 1873 to $2273 \mathrm{~K}$. By investigating the ignition and combustion behaviors of aluminum/magnesium alloy with diameter around $21 \mu \mathrm{m}$ in high temperature and pressure oxygen/nitrogen mixture, Roberts et al. [15] established an ignition model to evaluate

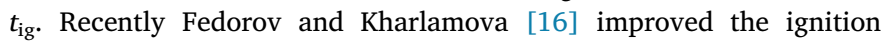
model of a single AMP, and provided the variation of pre-exponential factor of oxidation with ambient temperature and particle radius. These studies provide important references on AMP ignition. However, in the modeling of heat transfer between AMP and ambient gas, generally the continuum theory is adopted $[16,17]$. It may become inappropriate as the Knudsen number $(\mathrm{Kn})$, defined as the ratio of the mean free path of

\footnotetext{
* Corresponding authors.

E-mail addresses: liaohuanxin@hotmail.com (L. Liao), smashingsky@hotmail.com, shibaolu@bit.edu.cn (B. Shi).
} 


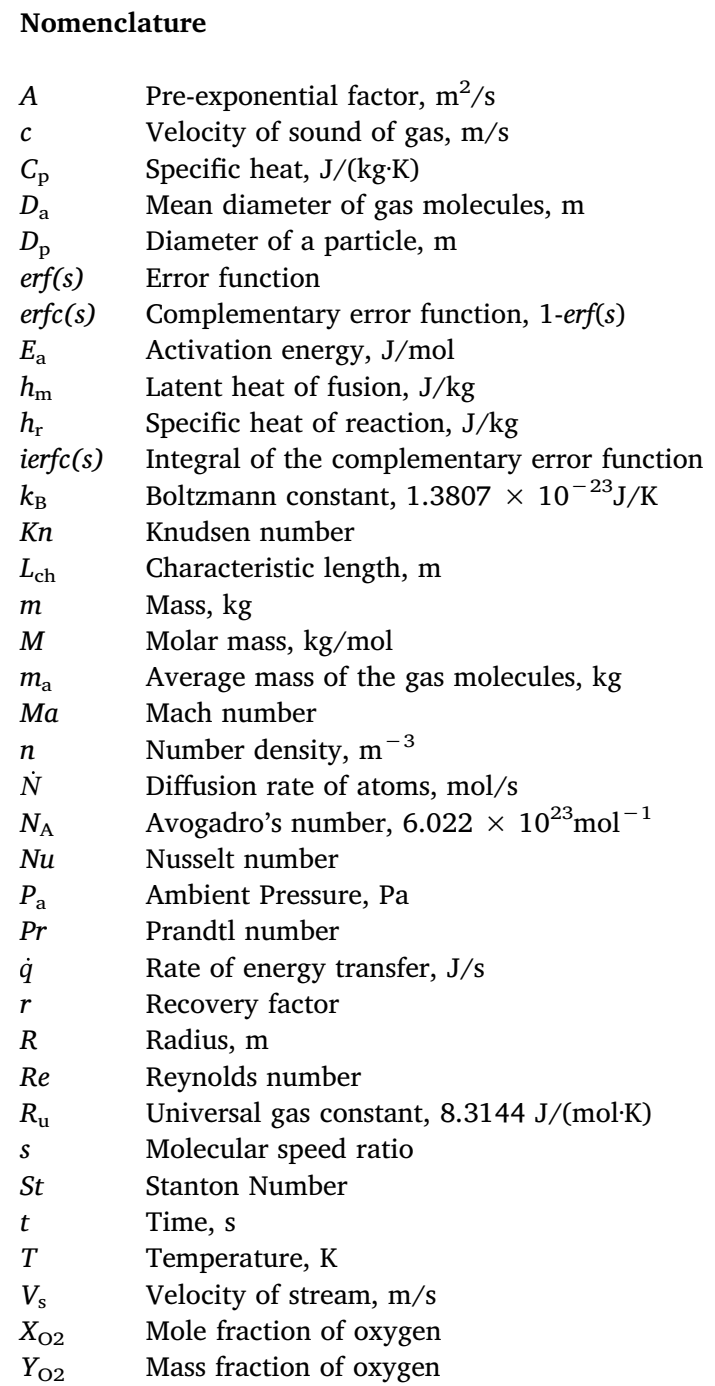

\section{Greek symbols}

$\alpha$

$\beta$

$\gamma$

$\delta$

$\varepsilon$

$\lambda$

$\mu$

$\mu_{\mathrm{s}}$

$\rho$

$\sigma$

$\omega$

\section{Subscripts}

$0 \quad$ Initial condition

a Ambient gas

Al Aluminum

c Core of aluminum particle

con Heat conduction or convection

cond Heat conduction

conv Heat convection

$\mathrm{Cm} \quad$ Continuum regime

Fm Free-molecular regime

fo Fast oxidation

ho Heterogeneous oxidation

ig Ignition condition

Kn Knudsen layer

L Liquid phase

m Melting

mix Mixture

out Outer region

Ox Aluminum oxide

p Particle

pre Preheating

rad Radiation heat transfer

s Stagnation condition

sur Surrounding solid surface

vhs Variable hard sphere ambient gas molecules to the particle diameter, is larger than 0.01 [18]. For example, in the $2000 \mathrm{~K}$ air atmosphere under the normal pressure, the critical AMP diameter is about $70 \mu \mathrm{m}$, below which the heat transfer should adopt the transition regime rather than the continuum regime [18].

On the other hand, for ANP ignition, which generally lies in the transition and free-molecular regimes, its heat transfer usually adopts the theory based on free-molecular regime [19]. While such relation only certainly effects as the particle diameter is below $70 \mathrm{~nm}$ in $2000 \mathrm{~K}$ air according to the critical condition of $K n=10$ [18]. Furthermore, so far there has been no scientific consensus on the oxidation mechanism during ANP ignition due to extremely small time and length scales. It is assumed that the oxidation and ignition of ANP is governed by the atomic diffusion across oxide shell, supported by a series of experiments $[17,20-23]$, theoretical analyses $[23,24]$ and even molecular dynamics simulation [25]. While Levitas et al. [26,27] proposed the melt dispersion mechanism for ANP reaction experiencing fast heating. They pointed out that the volume changing due to melting of $\mathrm{Al}$ induced pressure rise, resulting in spallation of the oxide shell and subsequent dispersion of liquid Al clusters. However, Li's [28] analysis of the alumina shell structure shows that the shell of ANPs does not break, but only deforms during oxidation. Chowdhury et al. [20] conducted experiments at high heating rates and concluded that ignition under the heating rates investigated has a diffusion governed mechanism.

Several studies have investigated metal particles ignition in the transition regime. A heating and ignition model of metal particles in transition regime was considered for a range of $\mathrm{Kn}$, which indicated that heat transfer rates were somewhat different from heating and cooling particle [29]. Sundaram et al. [30] summarized a comprehensive overview of ANP and AMP ignition, however, the heat transfer in transition regime was not analyzed in detail. Recently, Ermoline [31] simulated the thermal ignition of an aluminum particle by employing a single oxidation law for both ANP and AMP in the air, which revealed that the thermal accommodation coefficient (TAC) was a critical parameter for heat transfer modeling. Different methods were proposed to treat the heat conduction in transition regime. A comprehensive summary of the physics of heat conduction loss from a single spherical particle in the entire range of $K n$ has been provided by Liu et al. [18]. This study demonstrates that the boundary-sphere or two-layer method for transition regime, which was proposed by Langmuir [32] and applied by Fuchs [33], is capable of solving the problems with large temperature difference between the particle and ambient gas. With these methods, Liu et al. [18] established the heat conduction modelling in Laser-induced incandescence (LII) experiment of soot, in which the temperature of particle was much higher than the ambient gas. However, the heat transfer rate for a cold particle heated in the hot gas 
has yet been seldom examined and validated by the so-called exact methods like direct simulation Monte Carlo (DSMC) [34,35]. In addition, the temperature dependence of thermal conductivity and specific heat ratio should also be taken into consideration to yield an accurate model.

In summary, so far many theoretical models for the ignition of aluminum powder have been established. However, most of them are built for a limited range of particle sizes. Besides, the accuracy of the heat transfer model between the cold particle and high temperature environment needs to be improved, overcoming a lack of "calibration" under these conditions. In addition, in some applications such as ramjet or ICE, there is a relative velocity between the particle and the bulk gas, but few studies addressed the influences of bulk gas motion on the particle ignition over a wide size range. Moreover, an oxidation model suitable for ANP and AMP is also in great demand. The ignition model for ANP and AMP has become indispensable for the increasing need.

The main objective of this study is to establish an accurate ignition model applicable to aluminum powder including ANP and AMP. Firstly, a heat transfer model for ANP and AMP heated in quiescent/flow gas was built and validated by the DSMC and computational fluid dynamic (CFD) simulations; thereafter the oxidation model was developed, which was verified by the experiment data of critical ignition temperatures and ignition delay times. A parametric study was carried out to gain insights into the key factors influencing ignition properties, such as particle size, oxide thickness, emissivity, bulk gas velocity and oxygen concentration. Finally, in addition to ignition temperature, a prediction formula capable of predicting the ignition delay time was proposed and validated.

\section{Modeling and methodology}

\subsection{Modeling of heat transfer and oxidation}

A model describing heat transfer and oxidation processes during ignition of a spherical aluminum particle was firstly investigated. As schematically illustrated in Fig. 1, an aluminum particle with oxide layer is put into a high temperature ambient gas, which generally experiences heat conduction (or heat convection) and heat radiation with environment as well as aluminum oxidation. Since the Biot numbers for the core-shell ANP and AMP are orders of magnitude lower than unity [30], the lumped parameter method can be adopted to analyze the heat transfer. Accordingly, the governing equation of energy can be obtained and expressed as Eq. (1). Meanwhile, the melting process of aluminum core or alumina layer is described by Eq. (2).

$\frac{4}{3} \pi\left(\rho_{\mathrm{Al}} R_{\mathrm{c}}^{3} C_{\mathrm{p}-\mathrm{Al}}+\rho_{\mathrm{Ox}}\left(R_{\mathrm{p}}^{3}-R_{\mathrm{c}}^{3}\right) C_{\mathrm{p}-\mathrm{Ox}}\right) \frac{d T_{\mathrm{p}}}{d t}=\dot{q}_{\mathrm{con}}+\dot{q}_{\mathrm{rad}}+\dot{q}_{\mathrm{ho}}$ $h_{\mathrm{m}} \frac{d m_{\mathrm{p}-\mathrm{m}}}{d t}=\dot{q}_{\mathrm{con}}+\dot{q}_{\mathrm{rad}}+\dot{q}_{\mathrm{ho}}$

where $\rho_{\mathrm{Al}}$ and $\rho_{\mathrm{Ox}}$ are the densities of aluminum and alumina; $C_{\mathrm{p}-\mathrm{Al}}$ and $C_{\mathrm{p}-\mathrm{Ox}}$ account for the specific heat capacity of aluminum and alumina which are calculated by polynomials; and $R_{\mathrm{c}}$ and $R_{\mathrm{p}}$ represent the radius of aluminum core and particle, respectively. $T_{\mathrm{p}}$ is the particle temperature. $h_{\mathrm{m}}$ is the latent heat of fusion for aluminum or alumina, and $m_{\mathrm{p}-\mathrm{m}}$ is the mass of aluminum or alumina. $\dot{q}_{\mathrm{con}}$ and $\dot{q}_{\mathrm{rad}}$ represent conduction/convection and radiation rates, respectively; and $\dot{q}_{\mathrm{ho}}$ is the oxidation heat release rate.

It should be noted that regimes of heat conduction vary with particle size and ambient conditions, which are generally identified by Knudsen number $(K n)$, defined as the ratio of the mean free path $(\beta)$ of gas molecules to the characteristic length (Eq. (3) [30,34]).

$K n=\frac{\beta}{L_{\mathrm{ch}}}=\frac{R_{\mathrm{u}} T_{\mathrm{a}}}{\sqrt{2} \pi D_{\mathrm{a}}^{2} N_{\mathrm{A}} P_{\mathrm{a}} D_{\mathrm{p}}}$

where $L_{\mathrm{ch}}$ is characteristic dimension of a particle, which is defined as the particle diameter $D_{\mathrm{p}}$ in present study. $R_{\mathrm{u}}$ and $N_{\mathrm{A}}$ are the universal gas constant and Avogadro's number, respectively. $D_{\mathrm{a}}$ represents the mean diameter of ambient gas molecules. $T_{\mathrm{a}}$ and $P_{\mathrm{a}}$ are the temperature and pressure of ambient gas, respectively.

The continuum and free-molecular regimes are considered to prevail for $K n<0.01$ and $K n>10$ respectively, and the transition regime is proposed for $K n$ between 0.01 and 10 [18]. With decreasing $D_{\mathrm{p}}$ or increasing $T_{\mathrm{a}}$, the mean free path of gas molecules becomes comparable to the particle size, and the continuum regime evolves to transition or even free-molecular regimes. In transition regime, the region outside the particle is divided into two parts: (1) Knudsen region $\left(R_{p}<R<R_{\mathrm{Kn}}\right)$, in which there is no intermolecular collision and the heat transfer can be depicted by free-molecular regime, and (2) outer region with $R>R_{\mathrm{Kn}}$, where the continuum regime can be used to determine the heat and mass transfer. Here $R_{\mathrm{Kn}}$ is the radius of Knudsen layer.

In a condition considering heat convection, another expression can be employed [36], which is given as

$K n=\sqrt{\frac{\pi \gamma}{2}} \frac{M a}{R e}$

where $\gamma$ is specific heat ratio. $M a=V_{\mathrm{s}} / c$ is the March number and $R e=\rho_{\mathrm{a}} D_{\mathrm{p}} V_{\mathrm{s}} / \mu_{\mathrm{a}}$ is the Reynolds number. $V_{\mathrm{s}}$ and $c$ are flow velocity and sound velocity of gas; $\rho_{a}$ and $\mu_{a}$ are the density and viscosity of gas, respectively.

As for oxidation, the surrounding gas molecules diffuse towards the particle surface and they are absorbed at the surface; subsequently partial oxygen molecules/atoms diffuse into the oxide layer $[22,37,38]$.
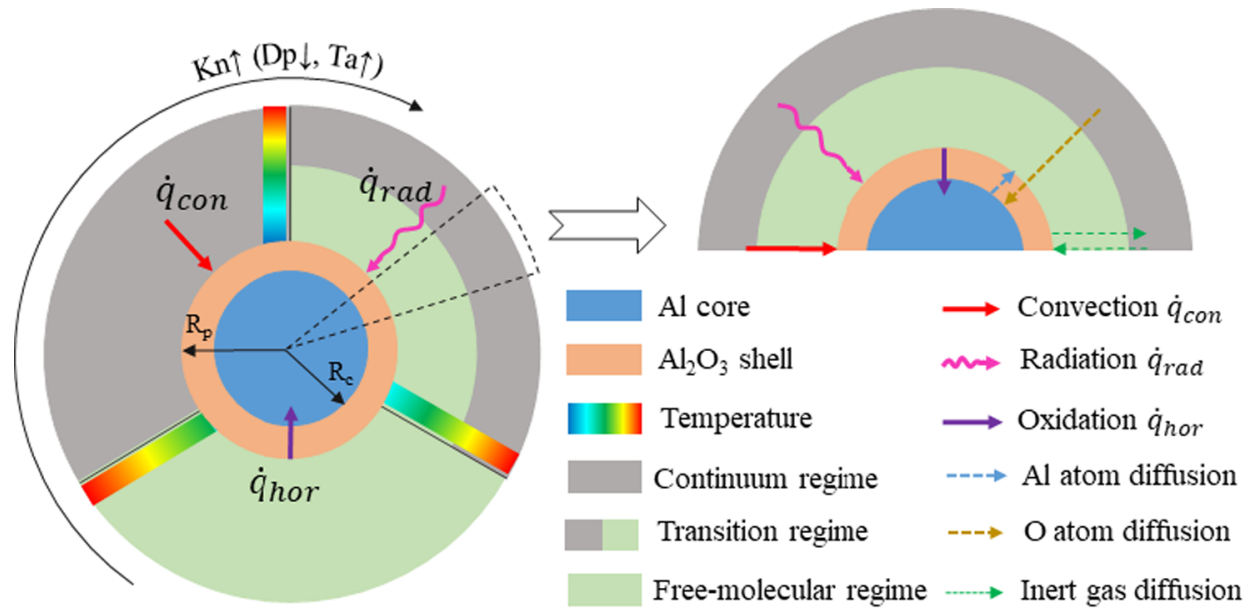

Fig. 1. Schematic model of heat and mass transfer for a single aluminum particle in hot gas. 
The core $\mathrm{Al}$ atoms diffuse outwards through the oxide layer as the core starts to melt. Following literatures $[17,21,39]$, in this study it is assumed that the oxidation process of aluminum is limited by the outward diffusion of core $\mathrm{Al}$ atoms, and the alumina is formed at the outer surface of aluminum particle.

\subsubsection{Governing equations for heat conduction}

The boundary conditions of temperature and gas component are treated as constant values at infinite. In the continuum regime, heat conduction is governed by Fourier's law through the following equation

$\dot{q}_{\text {cond }-\mathrm{Cm}}=2 \pi D_{\mathrm{p}} \int_{T_{\mathrm{p}}}^{T_{\mathrm{a}}} \lambda_{\mathrm{a}}(T) d T$

where $\dot{q}_{\text {cond - Cm }}$ is heat conduction rate in continuum regime, and $\lambda_{\mathrm{a}}(T)$ is the thermal conductivity of ambient gas. When the temperature difference between particle and surrounding gas is small, $\lambda$ a can be assumed as a constant at a given surrounding gas temperature [35]. However, as the temperature difference increases, a more rigorous form of heat conduction rate is proposed (Eq. (6)) via the averaged thermal conductivity $\lambda *$ a of gas between the particle and the gas temperature [18].

$\dot{q}_{\text {cond }-\mathrm{Cm}}=2 \pi D_{\mathrm{p}} \lambda_{\mathrm{a}}^{*}\left(T_{\mathrm{a}}-T_{\mathrm{p}}\right)$

where

$\lambda_{\mathrm{a}}^{*}=\frac{1}{T_{\mathrm{a}}-T_{\mathrm{p}}} \int_{T_{\mathrm{p}}}^{T_{\mathrm{a}}} \lambda_{\mathrm{a}}(T) d T$

In the free-molecular regime, a rigorous heat conduction form considering large temperature difference between the particle and surrounding gas is employed as [35]

$\dot{q}_{\text {cond - Fm }}=\alpha \pi D_{\mathrm{p}}^{2} \frac{P_{\mathrm{a}}}{8} \sqrt{\frac{8 k_{\mathrm{B}} T_{\mathrm{a}}}{\pi m_{\mathrm{a}}}}\left(\frac{\gamma^{*}+1}{\gamma^{*}-1}\right)\left(1-\frac{T_{\mathrm{p}}}{T_{\mathrm{a}}}\right)$

where $\dot{q}_{\text {cond - Fm }}$ is the heat conduction rate in free-molecular regime, and $\alpha$ is the thermal accommodation coefficient (TAC). $k_{\mathrm{B}}=1.3807 \times 10^{-23} \mathrm{~J} / \mathrm{K}$ is the Boltzmann constant, and $m_{\mathrm{a}}$ is the average mass of gas molecules. The mean specific heat ratio $\gamma^{*}$ is an average over the temperature range from $T_{\mathrm{p}}$ to $T_{\mathrm{a}}$, which is calculated by [35]

$\frac{1}{\gamma^{*}-1}=\frac{1}{T_{\mathrm{a}}-T_{\mathrm{p}}} \int_{T_{\mathrm{p}}}^{T_{\mathrm{a}}} \frac{1}{\gamma(T)-1} d T$

In the transition regime, Fuchs' approach [40] was adopted. The Knudsen region adjacent to the particle surface is supposed to be a thickness $\left(\beta_{\mathrm{Kn}}\right)$ approximated to the mean free path of gas molecules. The ratio of Knudsen layer to particle radius is given as [41]

$\frac{\beta_{\mathrm{Kn}}+R_{\mathrm{p}}}{R_{\mathrm{p}}}=\frac{R_{\mathrm{p}}^{2}}{\beta_{\mathrm{Kn}}^{2}}\left(\frac{1}{5} \Lambda_{1}^{5}-\frac{1}{3} \Lambda_{2} \Lambda_{1}^{3}+\frac{2}{15} \Lambda_{2}^{5 / 2}\right)$

where the interim parameters $\Lambda_{1}$ and $\Lambda_{2}$ are calculated by [41]

$\Lambda_{1}=1+\frac{\beta_{K n}}{R_{p}} ; \Lambda_{2}=1+\left(\frac{\beta_{K n}}{R_{p}}\right)^{2}$

Following the determination of the Knudsen layer, the heat conduction in the Knudsen region is calculated by Eq. (8), while that outside the Knudsen layer is calculated by Eq. (6). In transition regime, the key point is to solve $T_{\mathrm{Kn}}$ at Knudsen layer through energy conservation inside and outside Knudsen region, as

$\alpha \pi D_{\mathrm{p}}^{2} \frac{P_{a}}{8} \sqrt{\frac{8 k_{\mathrm{B}} T_{\mathrm{Kn}}}{\pi m_{\mathrm{a}}}}\left(\frac{\gamma^{*}+1}{\gamma^{*}-1}\right)\left(1-\frac{T_{\mathrm{p}}}{T_{\mathrm{Kn}}}\right)-2 \pi\left(D_{\mathrm{p}}+2 \beta_{\mathrm{Kn}}\right) \lambda_{\mathrm{a}}^{*}\left(T_{\mathrm{a}}-T_{\mathrm{Kn}}\right)=0$

\subsubsection{Governing equations for heat convection}

As mentioned above, the bulk gas motion influences heat transfer in many application scenarios. Here a model is proposed to describe heat convection. In the continuum regime, the equation can be derived by Eq. (6) based on the Nusselt number as given below

$\dot{q}_{\text {conv - Cm }}=\frac{N u_{\mathrm{p}}}{2} \dot{q}_{\text {cond - } \mathrm{Cm}}$

where $N u_{\mathrm{p}}$ is the surface averaged Nusselt number defined as the ratio of convection to pure conduction heat transfer. As for heat conduction of a spherical particle, $N u_{\mathrm{p}}=2$; and in a forced convection flow, Eq. (14) was employed to calculate $N u_{\mathrm{p}}$ [42].

$N u_{\mathrm{p}}=2+\left(0.4 R e_{\mathrm{p}}^{1 / 2}+0.06 \operatorname{Re}_{\mathrm{p}}^{2 / 3}\right) \operatorname{Pr}_{\mathrm{a}}^{0.4}\left(\mu_{\mathrm{a}} / \mu_{\mathrm{s}}\right)^{1 / 4}$

where $R e_{\mathrm{p}}=2 \rho_{a}\left|V_{\mathrm{a}}-V_{\mathrm{p}}\right| R_{\mathrm{p}} / \mu_{\mathrm{a}}$ is the particle Reynolds number, and $P r_{\mathrm{a}}=C_{\mathrm{p}} \mu_{\mathrm{a}} / \lambda_{\mathrm{a}}$ is the Prandtl number. The correlation is valid for $3.5 \leq R e_{\mathrm{p}} \leq 7.6 \times 10^{4}, 0.71 \leq P r_{\mathrm{a}} \leq 380$ and $1.0 \leq \mu_{\mathrm{a}} / \mu_{\mathrm{s}} \leq 3.2$.

The rarefied gas dynamics theory [43-45] was introduced in the free-molecular flow regime, and the heat transfer rate can be described as

$\dot{q}_{\text {conv - FM }}=\pi S_{\mathrm{t}} D_{\mathrm{p}}^{2} \rho_{\mathrm{a}} V_{\mathrm{s}} C_{\mathrm{p}}\left(T_{\mathrm{r}}-T_{\mathrm{p}}\right)$

where $T_{\mathrm{r}}$ is the recovery temperature, and $S t$ is Stanton Number calculated by

$S t=\frac{1}{8} \alpha \frac{\gamma^{*}+1}{\gamma^{*}}\left[1+\frac{1}{s} \operatorname{ierfc}(s)+\frac{1}{2 s^{2}} \operatorname{erf}(s)\right]$

where $s=V_{\mathrm{s}} / V_{\mathrm{m}}=\sqrt{\frac{\gamma}{2}} M a$ is the molecular speed ratio, and $V_{\mathrm{m}}$ is the most probable molecular speed. $\operatorname{erf}(s)=2 / \sqrt{\pi} \int_{0}^{s} e^{-x^{2}} d x$ is error function. $\operatorname{erfc}(s)=1-\operatorname{erf}(s)$ and $\operatorname{ierfc}(s)=\int_{s}^{\infty} \operatorname{erfc}(x) d x$ are the complementary error function and integral of the complementary error function, respectively. As $s$ approaches zero, the limit of Eq. (15) approximates to Eq. (8).

The recovery temperature is given as

$T_{\mathrm{r}}=T_{\mathrm{a}}+r\left(T_{\mathrm{s}}-T_{\mathrm{a}}\right)$

where $T_{\mathrm{s}}$ is the stagnation temperature, and $r$ is recovery factor which can be calculated by

$r=\frac{\gamma *}{\gamma *+1} \frac{\left(2 s^{2}+1\right)\left(1+\frac{1}{s} \operatorname{ierfc}(s)\right)+\left(1-\frac{1}{2 s^{2}}\right) \operatorname{erf}(s)}{s^{2}\left(1+\frac{1}{s} \operatorname{ierfc}(s)+\frac{1}{2 s^{2}} \operatorname{erf}(s)\right)}$

In the transition regime, a correlation was employed to calculate the heat convection rate $[45,46]$ through

$\frac{S t}{S t_{\mathrm{Fm}}}=\left[1+\left(S t_{\mathrm{Fm}} / S t_{\mathrm{Cm}}\right)\right]^{-1}$

where $S t_{\mathrm{Fm}}$ and $S t_{\mathrm{Cm}}$ are the limiting values of free-molecular flow and the continuum flow respectively, which are given as

$\left\{\begin{array}{l}S t_{\mathrm{Fm}}(M a)=\lim _{R e \rightarrow 0} S t(M a, R e) \\ S t_{\mathrm{Cm}}(R e)=\lim _{M a \rightarrow 0} S t(M a, R e)\end{array}\right.$

\subsubsection{Heat radiation}

It is assumed that the radiation heat exchange occurs between a small particle surface with temperature $T_{\mathrm{p}}$ and a surrounding isothermal solid wall surface with temperature $T_{\text {sur }}$ that completely covers the particle and ambient gas. Then the net rate of heat radiation can be expressed as

$\dot{q}_{\mathrm{rad}}=\pi D_{\mathrm{p}}^{2} \varepsilon \sigma\left(T_{\mathrm{sur}}^{4}-T_{\mathrm{p}}^{4}\right)$

where $\sigma=5.67 \times 10^{-8} \mathrm{~W} /\left(\mathrm{m}^{2} \mathrm{~K}^{4}\right)$ is the Stefan-Boltzmann constant, and $\varepsilon$ is the emissivity of aluminum or alumina, generally given as 0.1 [30] or 0.3 [47]. In the current prediction, it is assumed that $T_{\text {sur }}=T_{\mathrm{a}}$, 
which to some extent is consistent with the actual situation.

\subsubsection{Governing equations for aluminum oxidation}

The heat release from aluminum oxidation is obtained by the mass consumption rate of aluminum core as

$\dot{q}_{\mathrm{ho}}=h_{\mathrm{r}} \frac{d m_{\mathrm{Al}}}{d t}$

where $h_{\mathrm{r}}=3.1 \times 10^{7} \mathrm{~J} / \mathrm{kg}$ is specific heat of heterogeneous oxidation between aluminum and oxygen [15].

Before particle ignition, the oxidation of aluminum is controlled by the diffusion of $\mathrm{Al}$ and $\mathrm{O}$ atoms, as described in Fig. 1. The exothermic oxidation before ignition has been described by several kinetics schemes $[15,16]$. The Parabolic law [16] was employed to depict the oxidation rate for both ANP and AMP in the present study, which takes into account the diffusion of $\mathrm{Al}$ atoms passed through the oxide layer and the oxygen concentration in atmosphere. The equation is presented as

$\frac{d \delta}{d t}=\frac{A X_{O_{2}}}{\delta} \exp \left(-E_{a} / R_{u} T_{p}\right)$

where $\delta$ is the thickness of aluminum oxide. $X_{\mathrm{O} 2}$ represents the mole fraction of oxygen molecules. $A$ and $E_{\mathrm{a}}$ are the pre-exponential factor and activation energy, respectively. According to Eq. (23), the mass consumption rate of aluminum core is given as

$\frac{d m_{\mathrm{Al}}}{d t}=\left(\frac{2 M_{\mathrm{Al}}}{M_{\mathrm{Ox}}}\right) 4 \pi R_{\mathrm{p}}^{2} \rho_{\mathrm{Ox}} \frac{d \delta}{d t}$

For AMP, two sets of data at higher and lower temperatures were employed to fit the kinetics parameters of current model. For $T_{\mathrm{a}}=1873 \mathrm{~K}$ to $2273 \mathrm{~K}$ (i.e., relatively high temperature), the kinetics in Ref. [14] was adopted. Around the melting temperature of aluminum (i.e., relatively low temperature), the rate of aluminum oxidation was given in the form of a radial diffusion equation as Eq. (25) [17], which was further converted to Eq. (26) to present the similar expression as Eq. (23).

$\dot{N}_{\mathrm{Al}}=\frac{4 \pi\left|C_{\mathrm{ox}}-C_{\mathrm{Al}}\right| A_{1} \exp \left(-E_{\mathrm{a} 1} / R_{\mathrm{u}} T_{\mathrm{p}}\right)}{1 / R_{\mathrm{c}}-1 / R_{\mathrm{p}}}$

$\frac{d \delta}{d t}=\frac{a M_{\mathrm{Ox}}\left|C_{\mathrm{ox}}-C_{\mathrm{Al}}\right| A_{\mathrm{Al}}}{2 \rho_{\mathrm{Ox}} X_{\mathrm{O}_{2}}} \frac{X_{\mathrm{O}_{2}}}{\delta} \exp \left(-E_{\mathrm{a}} / R_{\mathrm{u}} T_{\mathrm{p}}\right)$

where $C_{\mathrm{Al}}$ and $C_{\mathrm{ox}}$ are $\mathrm{Al}$ concentrations on the interfaces of aluminum/ oxide and oxide/oxidizer, respectively. By comparing the coefficients in Eqs. (23) and (26), the oxidation parameters for AMP were obtained and fitted via the data at both low [17] and high temperatures [14], which were given as a function of $T_{\mathrm{p}}$, as $A=1.6667 \times 10^{-12} T_{\mathrm{p}^{-}}$ $1.5550 \times 10^{-9} \mathrm{~m}^{2} / \mathrm{s}$ and $E_{\mathrm{a}}=71060 \mathrm{~J} / \mathrm{mol}$. For ANP, the oxidation kinetics parameters were fitted via the results of Ref. [39], which were given as $A=2.45 \times 10^{-11} \mathrm{~m}^{2} / \mathrm{s}, E_{\mathrm{a}}=35218 \mathrm{~J} / \mathrm{mol}$. For the particles with diameter between $100 \mathrm{~nm}$ and $1 \mu \mathrm{m}$, a linear interpolation formula based on diameter was proposed to characterize the oxidation kinetics to acquire the oxidation model.

\subsection{Coefficients in modeling}

The properties of aluminum and alumina used in the present model are listed in Table $1[48,49]$. The heat capacities of gas, aluminum and alumina were calculated by polynomial equation and the coefficients were referenced from Ref. [50]. The conductivity coefficients and viscosity coefficients of argon, oxygen and nitrogen at 300-4000 K under normal pressure were calculated by Cantera codes [51] based on thermal database of GRI-Mech 3.0. Since thermal dissociation of species is a very slow process [18], the dissociation of species is ignored in this study. The present calculation shows a good agreement with the conductivity of air [18] and other data in Refs. [52-54]. Cubic polynomial formulas $\left(C o=a_{0}+a_{1} T+a_{2} T^{2}+a_{3} T^{3}\right)$ for conductivity and viscosity were fitted based on the calculated results and the coefficients are listed in Table 2.

The properties of the mixture were calculated from the constituent gases. For instance, the thermal conductivity [51], thermal accommodation coefficient [55] and molecular mean free path [34] of the mixture were calculated through Eqs. (27)-(29), respectively.

$\lambda_{\text {mix }}=0.5\left(\sum_{\mathrm{i}=1}^{s} X_{\mathrm{i}} \lambda_{\mathrm{i}}+\frac{1}{\sum_{\mathrm{i}=1}^{s} X_{\mathrm{i}} / \lambda_{\mathrm{i}}}\right)$

$\alpha_{m i x}=\frac{\sum_{\mathrm{i}=1}^{s}\left(X_{\mathrm{i}} \alpha_{\mathrm{i}}\right) /\left(\sqrt{M_{\mathrm{i}}}\right)}{\sum_{\mathrm{i}=1}^{s}\left(X_{\mathrm{i}}\right) /\left(\sqrt{M_{\mathrm{i}}}\right)}$

$\beta_{\text {mix }}=\sum_{\mathrm{i}=1}^{s}\left(\frac{n_{\mathrm{i}}}{n} \beta_{\mathrm{i}}\right)$

\subsection{Methodology}

\subsubsection{CFD and DSMC methods}

The computational fluid dynamic (CFD) and direct simulation Monte Carlo (DSMC) methods were employed to validate the heat conduction and convection between a cold particle and hot gas. The former verifies heat transfer in continuum and the latter supports heat transfer validity in transition and free-molecular regimes. The governing equations of CFD simulation were the same as Ref. [56] and the laminar flow model was employed. In DSMC, a particle-based method proposed by Bird [34] was used to simulate the real gas flow by tracking the movement of a finite number of simulated particles, allowing to capture the physical properties of the gas by decoupling particle motion and collision.

The geometries of CFD and DSMC simulations consisted of a sphere lying in the center and a surrounding region filled with high temperature gas. The size of the outer region was determined by [35]

$R_{\text {out }}=\left\{\begin{array}{l}5\left(\beta_{\text {vhs }}+R_{\mathrm{p}}\right), K n<5 \\ 2 \beta_{\mathrm{vhs}}, K n \geqslant 5\end{array}\right.$

where $\beta_{\mathrm{vhs}}$ is the mean free path of the variable hard sphere (VHS) model for elastic collisions. The dsmcFoam + solver, an open-source program package implemented within the OpenFOAM $[57,58]$, was employed in DSMC simulation. The boundaries of sphere and outer surface of surrounding gas were set as walls with individual constant temperatures. Because the temperature of outer boundary of computational domain was not known in advance, a simple boundary condition was employed $[18,35]$ and a Linux shell was written to dynamically update the boundary conditions until the energy conservation was achieved between the outer boundary and particle surface. In the simulation, the number of collisions was determined by no-time-counter (NTC) scheme, and $\beta_{\text {vhs }}$ can be given by Eq. (31) [58]. The Maxwell model was used to deal with the interactions between gas molecules

Table 1

Properties of aluminum and alumina used in the model.

\begin{tabular}{ll}
\hline Parameters & Values \\
\hline$\rho_{\mathrm{Al}}\left(\mathrm{kg} / \mathrm{m}^{3}\right)$ & $2700[48]$ \\
$\rho_{\mathrm{L}-\mathrm{Al}}\left(\mathrm{kg} / \mathrm{m}^{3}\right)$ & $2377[30]$ \\
$T_{\mathrm{m}-\mathrm{Al}}(\mathrm{K})$ & $933.5[49]$ \\
$h_{\mathrm{m}-\mathrm{Al}}(\mathrm{J} / \mathrm{kg})$ & $396976.6[49]$ \\
$\rho_{\mathrm{Ox}}\left(\mathrm{kg} / \mathrm{m}^{3}\right)$ & $3970[48]$ \\
$T_{\mathrm{m}-\mathrm{Ox}}(\mathrm{K})$ & $2327.0[49]$ \\
$h_{\mathrm{m}-\mathrm{Ox}}(\mathrm{J} / \mathrm{kg})$ & $1161295.7[49]$ \\
\hline
\end{tabular}


Table 2

Polynomial fitting coefficients for conductivity and viscosity of gases.

\begin{tabular}{|c|c|c|c|c|c|}
\hline \multirow[t]{2}{*}{ Items } & \multirow[t]{2}{*}{ Gases } & \multicolumn{4}{|l|}{ Coefficients } \\
\hline & & $\mathrm{a}_{0}$ & $\mathrm{a}_{1}$ & $\mathrm{a}_{2}$ & $a_{3}$ \\
\hline \multirow[t]{3}{*}{ Conductivity } & $\mathrm{Ar}$ & 0.00763517 & $4.17655863 \times 10^{-05}$ & $-7.11636674 \times 10^{-09}$ & $7.26172334 \times 10^{-13}$ \\
\hline & $\mathrm{O}_{2}$ & 0.00661439 & $7.40453369 \times 10^{-05}$ & $-8.88947394 \times 10^{-09}$ & $8.61253353 \times 10^{-13}$ \\
\hline & $\mathrm{N}_{2}$ & 0.00528017 & $7.17896488 \times 10^{-05}$ & $-9.01829866 \times 10^{-09}$ & $7.14383968 \times 10^{-13}$ \\
\hline \multirow[t]{3}{*}{ Viscosity } & $\mathrm{Ar}$ & $9.76442707 \times 10^{-06}$ & $5.35380141 \times 10^{-08}$ & $-9.12866853 \times 10^{-12}$ & $9.31738857 \times 10^{-16}$ \\
\hline & $\mathrm{O}_{2}$ & $9.33270091 \times 10^{-06}$ & $4.48159679 \times 10^{-08}$ & $-7.38877704 \times 10^{-12}$ & $7.43110469 \times 10^{-16}$ \\
\hline & $\mathrm{N}_{2}$ & $8.34284078 \times 10^{-06}$ & $3.85307226 \times 10^{-08}$ & $-6.27740809 \times 10^{-12}$ & $6.27799630 \times 10^{-16}$ \\
\hline
\end{tabular}

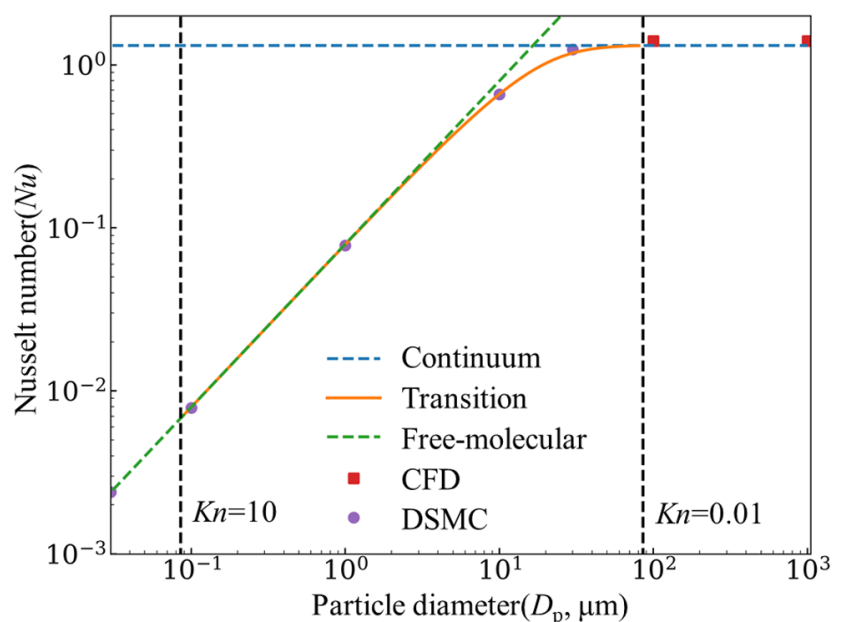

Fig. 2. Comparison of Nusselt number in heat conduction acquired by theoretical model and CFD/DSMC simulations.

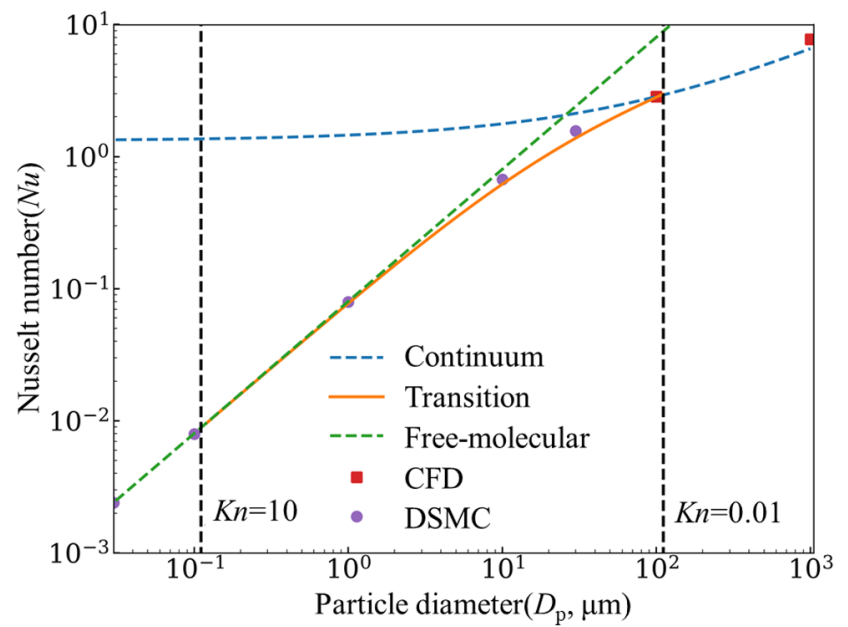

Fig. 3. Nusselt number in heat convection acquired by theoretical model and CFD/DSMC simulations.

and particle surface.

$\beta_{\text {vhs }}(T)=\frac{2(5-2 \omega)(7-2 \omega)}{15}\left(\frac{m_{\mathrm{a}}}{2 \pi k_{\mathrm{B}} T}\right)^{0.5}\left(\frac{\mu_{\mathrm{a}}}{\rho_{\mathrm{a}}}\right)$

where $\omega$ is the temperature coefficient of viscosity.

\subsubsection{Machine learning method}

This ignition model established in the current study is capable of calculating $t_{\mathrm{ig}}$ by varying parameters like $D_{\mathrm{p}}, T_{\mathrm{a}}$ and so on. Therefore, based on plenty of data calculated by the present model, a prediction model is proposed via machine learning method to acquire $t_{\mathrm{ig}}$. The

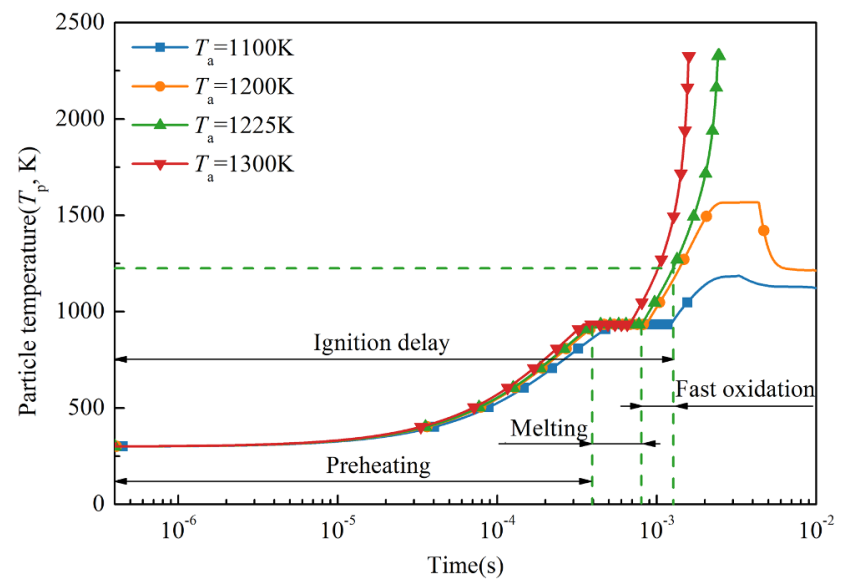

Fig. 4. Temperature profiles of aluminum particle $(3.16 \mu \mathrm{m})$ in different ambient temperatures indicating success or failure of ignition.

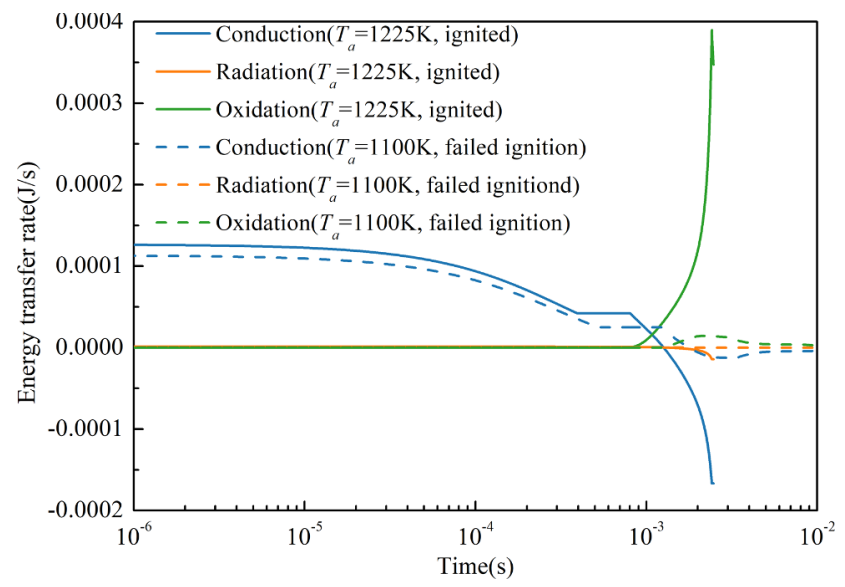

Fig. 5. Temporal variation of energy transfer rates for successful and failed particle ignition.

statistical model is assumed to be

$y=\sum_{\mathrm{i}=0}^{2} \sum_{\mathrm{j}=0}^{2} a_{\mathrm{ij}} x_{1}^{\mathrm{i}} x_{2}^{\mathrm{j}}$

where $x_{1}$ and $x_{2}$ are two features, and $a_{\mathrm{ij}}$ is the parameter. Though this model implements a binary quadratic function as its input, the output is still a linear function of the parameters, and the model can be trained with linear regression method. In the present study the ordinary least squares method was used to train the model [59]. 


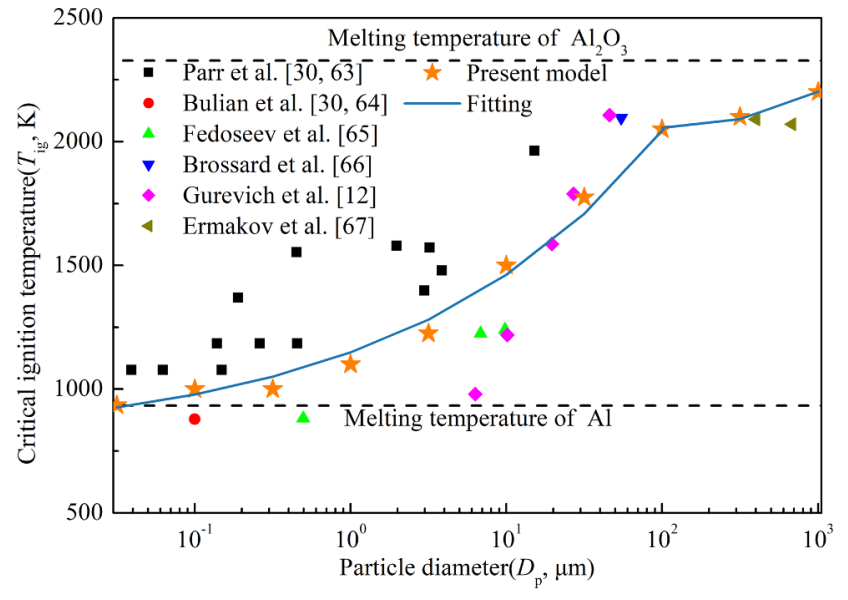

Fig. 6. Comparison of ignition temperatures between present model and experimental results [12,30,63-67].

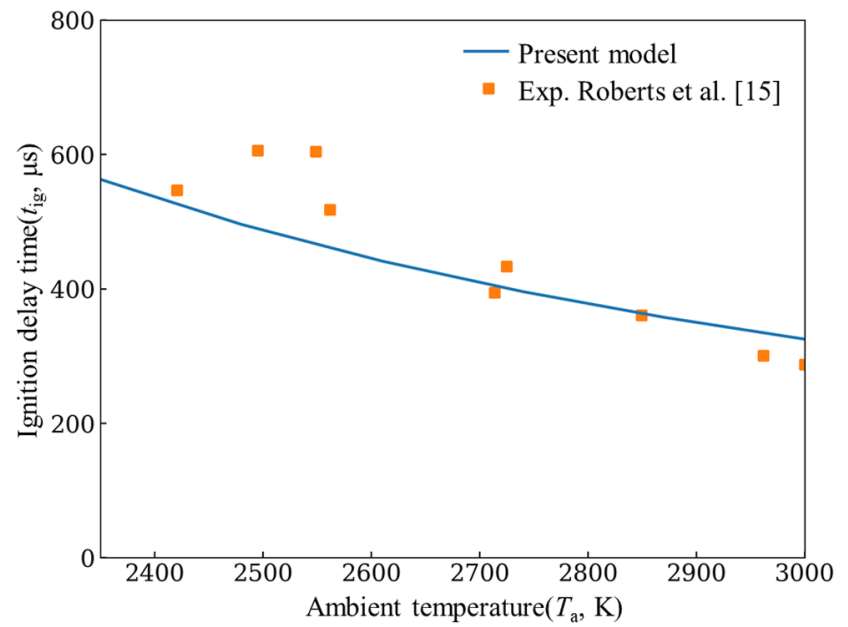

Fig. 7. Comparison of ignition delay times of present model and measurements from Ref. [15].

\section{Results and discussion}

\subsection{Validation of heat transfer}

The accuracy of heat transfer model directly influences the precision of ignition prediction. Thus heat conduction rates $\left(\dot{q}_{c o n}\right)$ acquired by the current model (calculated by Eqs. (6), (8) and (12)) were compared with DSMC $(K n>0.01)$ and CFD $(K n \leq 0.01)$ simulations in terms of Nusselt number defined in Eq. (33). The results for heat conduction are plotted in Fig. 2. The values of $D_{\mathrm{p}}$ were varied from 0.03 to $1000 \mu \mathrm{m}$ and argon was employed as the surrounding gas with $T_{\mathrm{a}}=3000 \mathrm{~K}$ and $P_{\mathrm{a}}=1 \mathrm{~atm}$. The TAC between particle surface and gas molecules was selected as 0.33 [60]. It is seen that the theoretical model shows a good agreement with CFD simulation ( $\boldsymbol{\square}$ ) in continuum regime and DSMC simulation ( $)$ in transition as well as free-molecular regime. Particularly, the heat conduction between $D_{\mathrm{p}}=1$ to $100 \mu \mathrm{m}$ is well acquired where both continuum and free-molecular regimes cannot yield an accurate $\mathrm{Nu}$.

$N u=\frac{\dot{q}_{\text {con }}}{\pi D_{\mathrm{p}} \lambda_{\mathrm{a}}\left(T_{\mathrm{a}}\right)\left(T_{\mathrm{a}}-T_{\mathrm{p}}\right)}$

In addition, heat convection rates for a particle in flowing gas were also examined, as illustrated in Fig. 3. The results reveal that the current theoretical model can accurately depict the heat transfer rate for a wide range of particle sizes.

\subsection{Critical ignition temperature}

With validated heat transfer models, the ignition process of a single aluminum particle was analyzed by monitoring the temporal variation of $T_{\mathrm{p}}$. As an example, the particle with $D_{\mathrm{p}}=3.16 \mu \mathrm{m}$ and $T_{\mathrm{p} 0}=300 \mathrm{~K}$ was put into quiescent air under $1 \mathrm{~atm}$. The ambient air temperature was gradually increased from $T_{\mathrm{a}}=1100 \mathrm{~K}$ to determine the critical temperature for particle ignition. The TAC between the aluminum particle and surrounding gas was selected as 0.07 , which was measured by Allen for ANP in nitrogen atmosphere [61]. This value is reasonable as air mainly consists of nitrogen and the upper limits of TAC [62] for oxygen and nitrogen are close to each other.

For $T_{\mathrm{a}}=1100 \mathrm{~K}$, as plotted in Fig. $4, T_{\mathrm{p}}$ gradually increases from $T_{\mathrm{p} 0}$ to the melting point of aluminum $\left(T_{\mathrm{m}-\mathrm{Al}}\right)$; this process is defined as preheating stage with a corresponding duration $t_{\text {pre. }}$. Then the value of $T_{\mathrm{p}}$ maintains constant $\left(T_{\mathrm{m}-\mathrm{Al}}\right)$ until complete melting of aluminum core, which is defined as melting stage with its duration of $t_{\mathrm{m}}$. Subsequently, $T_{\mathrm{p}}$ continues to rise and thereafter drops, indicating failure of ignition. Subsequently, $T_{\mathrm{a}}$ is raised to $1200 \mathrm{~K}$ to monitor the temporal variation of $T_{\mathrm{p}}$. The similar phenomenon is observed except that the preheating stage is slightly shortened and the peak value of $T_{\mathrm{p}}$ increases. As $T_{\mathrm{a}}$ increases to $1225 \mathrm{~K}$, at the end of melting stage, $T_{\mathrm{p}}$ illustrates a remarkable increase beyond $2000 \mathrm{~K}$, indicating that the particle is successfully ignited. This temperature is defined as the critical ignition temperature $\left(T_{\mathrm{ig}}\right)$ corresponding to specific size particle. As $T_{\mathrm{a}}$ further increases, the aluminum particle is ignited within a shorter duration.

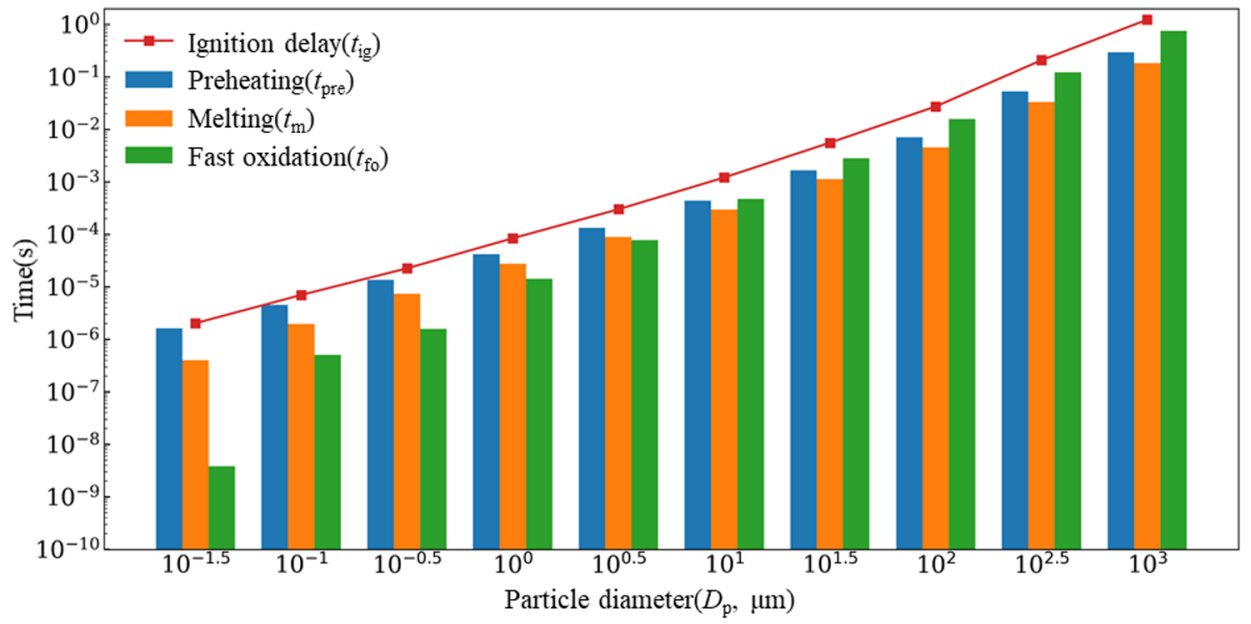

Fig. 8. Ignition delay times and corresponding durations in preheating, melting and fast oxidation stages $\left(T_{\mathrm{p} 0}=300 \mathrm{~K}, T_{\mathrm{a}}=2500 \mathrm{~K}\right.$ and $P_{\mathrm{a}}=1$ atm). 


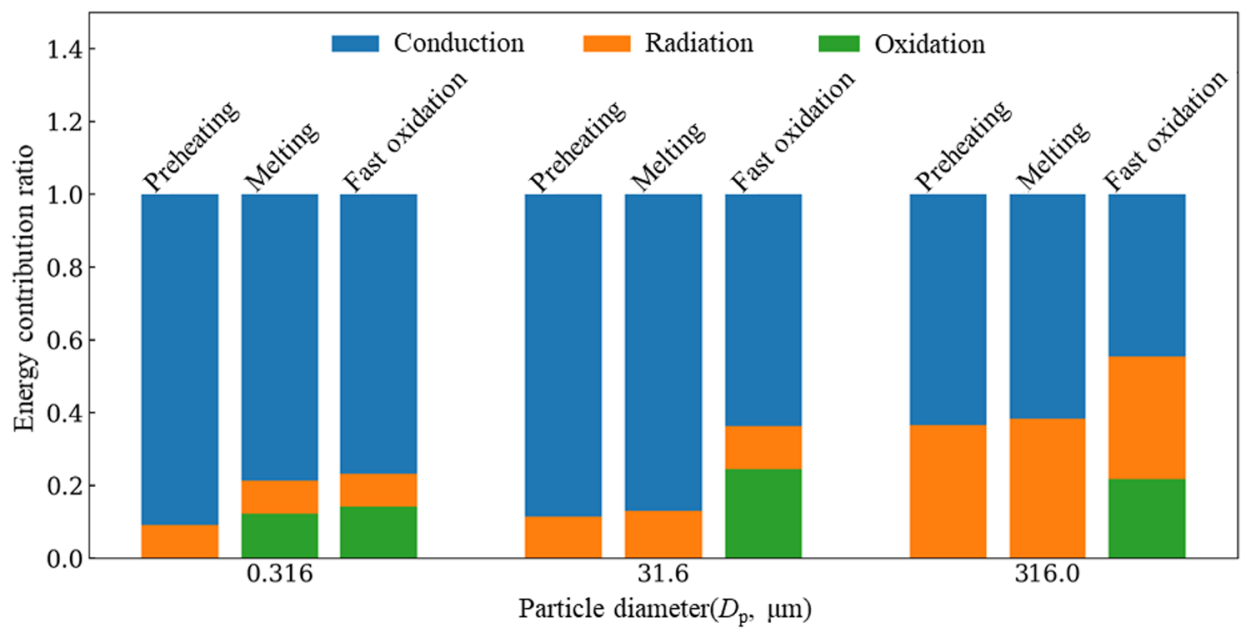

Fig. 9. Energy contribution ratio in each stage for typical particle sizes $\left(T_{\mathrm{p} 0}=300 \mathrm{~K}, T_{\mathrm{a}}=2500 \mathrm{~K}\right.$ and $P_{\mathrm{a}}=1$ atm $)$.
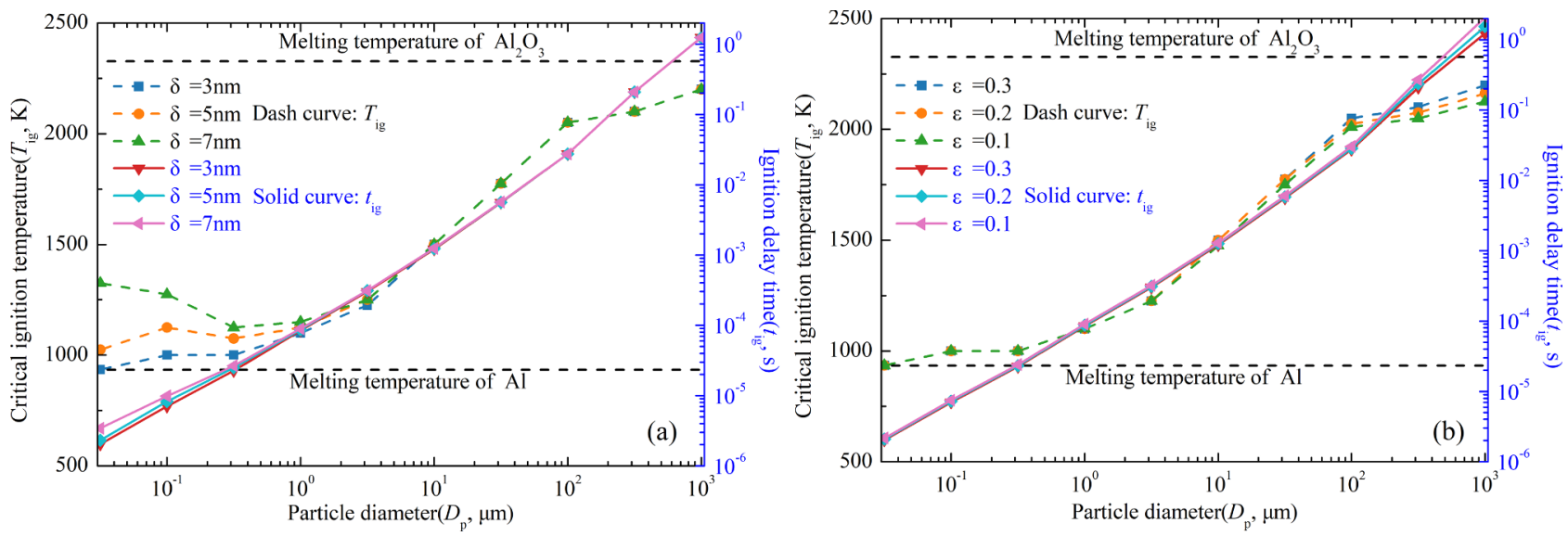

Fig. 10. Effects of oxide layer thickness (a) and particle emissivity (b) on particle ignition in a variety of sizes.
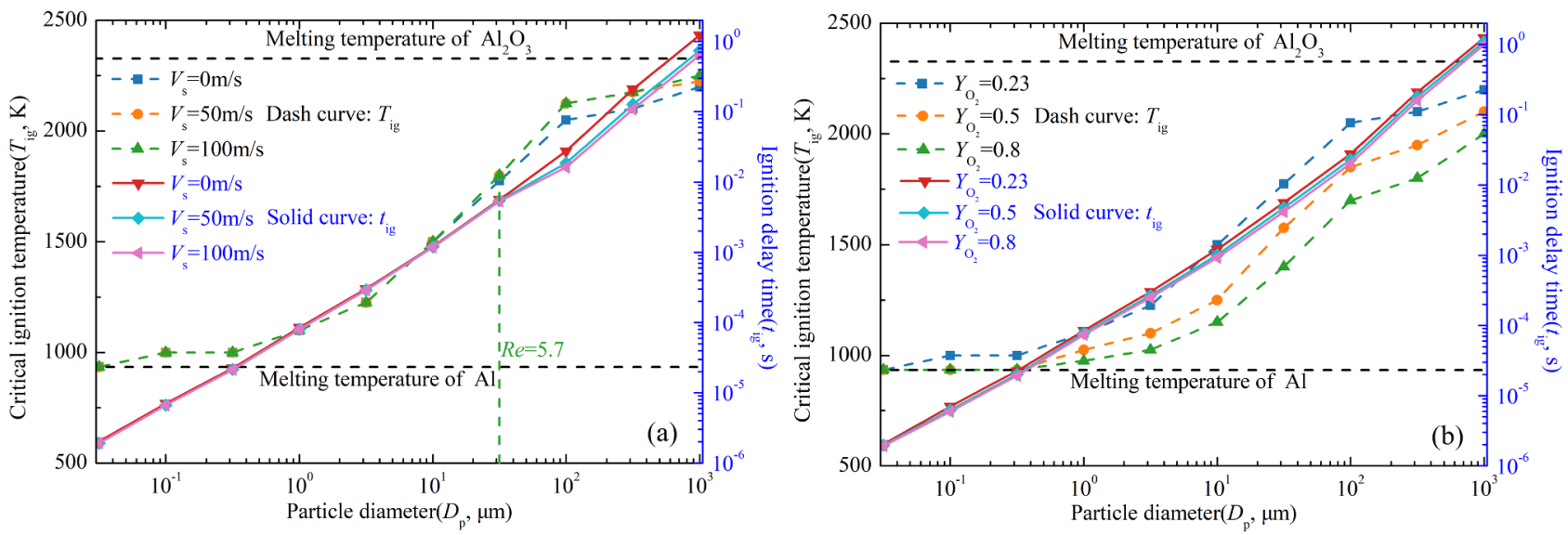

Fig. 11. Influences of bulk flow velocity (a) and oxygen concentration (b) on particle ignition.

For the case of successful ignition, another duration from the end of melting to the instant where $T_{\mathrm{p}}$ approaches $T_{\mathrm{ig}}$ is defined as the fast oxidation $\left(t_{\mathrm{fo}}\right)$. Furthermore, the whole duration as $T_{\mathrm{p}}$ increases from $T_{\mathrm{p} 0}$ to $T_{\mathrm{ig}}$ is defined as ignition delay time $\left(t_{\mathrm{ig}}\right)$, i.e., $t_{\mathrm{ig}}=t_{\mathrm{pre}}+t_{\mathrm{m}}+t_{\mathrm{fo}}$.

More details concerning the contributions of heat conduction and radiation as well as oxidation heat release to particle ignition are examined by comparing their corresponding rates in two cases of $T_{\mathrm{a}}=1100$ and $1225 \mathrm{~K}$ (Fig. 5). It can be seen that the heat conduction dominates in the preheating and melting stages regardless success (solid curves) or failure (dash curves) of ignition. In the case of successful ignition, the heat release rate of oxidation shows a sharp increase, directly leading to ignition. Owing to a rapid increase of $T_{\mathrm{p}}$, heat is transferred from particle to surrounding, as the negative value of heat conduction rate indicated.

With the similar method, $T_{\text {ig }}$ was determined for both ANP and AMP burning in air, as plotted in Fig. 6 . The results based on present model $(\star)$ show a reasonable agreement with experimental data [12,30,63-67]. At the nanoscale, owing to differences in experimental 
Table 3

Coefficients for prediction formula (Eq. (35)).

\begin{tabular}{ll}
\hline Coefficients & Values \\
\hline $\mathrm{a}_{00}$ & -3.7194 \\
$\mathrm{a}_{01}$ & $-1.7333 \times 10^{-4}$ \\
$\mathrm{a}_{02}$ & $1.3516 \times 10^{-9}$ \\
$\mathrm{a}_{10}$ & 1.2068 \\
$\mathrm{a}_{11}$ & $-3.7939 \times 10^{-5}$ \\
$\mathrm{a}_{12}$ & $3.7993 \times 10^{-9}$ \\
$\mathrm{a}_{20}$ & $2.4279 \times 10^{-1}$ \\
$\mathrm{a}_{21}$ & $-8.2305 \times 10^{-5}$ \\
$\mathrm{a}_{22}$ & $8.1993 \times 10^{-9}$ \\
\hline
\end{tabular}

conditions and difficulties in measurement, $T_{\mathrm{ig}}$ from experiments shows deviation with each other, while the current calculations lie in the range of them and the calculated $T_{\mathrm{ig}}$ is slightly higher than $T_{\mathrm{m}-\mathrm{Al}}$, which is also consistent with general viewpoint of ignition temperature for ANP [30]. The computed $T_{\text {ig }}$ rapidly decreases as $D_{\mathrm{p}}$ drops from 100 to $1 \mu \mathrm{m}$, which coincides with results of Ref. [12]. Furthermore, based on the results of present model, a formula is fitted to capture $T_{\mathrm{ig}}$ for ANP and AMP ignited in air as

$T_{\mathrm{ig}}=\left\{\begin{array}{l}368 D_{\mathrm{p}}^{0.268}+780, D_{\mathrm{p}} \leqslant 100 \mu m \\ 0.1617 D_{\mathrm{p}}+2040,100 \mu \mathrm{m}<D_{\mathrm{p}} \leqslant 1000 \mu m\end{array}\right.$

\subsection{Ignition delay time}

Next, the ignition delay time was examined for both ANP and AMP. The $t_{\mathrm{ig}}$ acquired by the present model is compared with the experimental data [15] obtained in a reflected shock tube (assuming $T_{\text {sur }}=300 \mathrm{~K}$ ) for a series of $T_{\mathrm{a}}$ between 2400 and $3000 \mathrm{~K}$. The aluminum particles with $D_{\mathrm{p}}=21.7 \mu \mathrm{m}$ were ignited in a mixture containing $99 \% \mathrm{O}_{2}$ and $1 \% \mathrm{~N}_{2}$, in which $t_{\mathrm{ig}}$ was determined by measuring particle radiation signal. Firstly, $T_{\mathrm{ig}}$ corresponding to $D_{\mathrm{p}}=21.7 \mu \mathrm{m}$ was determined as $T_{\mathrm{ig}}=1850 \mathrm{~K}$ through the current model, indicating that the particles can be ignited in the high temperature shock tube; then $t_{\mathrm{ig}}$ was calculated for different $T_{\mathrm{a}}$ corresponding to experimental condition. The calculated $t_{\text {ig }}$ is compared with measurements, as plotted in Fig. 7. The result reveals that the current model can reasonably predict $t_{\text {ig. }}$

Multiple sized particles with $\delta=3 \mathrm{~nm}$ and $T_{\mathrm{p} 0}=300 \mathrm{~K}$ were selected to examine their ignition characteristics in a quiescent air with $T_{\mathrm{a}}=2500 \mathrm{~K}$ and $P_{\mathrm{a}}=1 \mathrm{~atm}$. The TAC and emissivity were selected as $\alpha=0.07$ [61] and $\varepsilon=0.3$ [47] as mentioned before. Fig. 8 shows the results of $t_{\mathrm{ig}}(\mathbb{\square})$ against $D_{\mathrm{p}}$, and the corresponding values of $t_{\mathrm{pre}}, t_{\mathrm{m}}$ and $t_{\mathrm{fo}}$ are presented with histogram. As $D_{\mathrm{p}}$ increases from 0.03 to $1000 \mu \mathrm{m}$, $t_{\mathrm{ig}}$ rapidly increases from $1 \mu \mathrm{s}$ to $1 \mathrm{~s}$. Generally, $t_{\mathrm{pre}}$ dominates the ignition delay process, particularly for ANP ignition; as $D_{\mathrm{p}}$ raises to above $1 \mu \mathrm{m}, t_{\mathrm{pre}}, t_{\mathrm{m}}$ and $t_{\mathrm{fo}}$ are almost at the same level. Therefore, here a convenient method is proposed to roughly predict $t_{\mathrm{ig}}$, as $t_{\mathrm{ig}}=2 t_{\mathrm{pre}}$ for ANP and $t_{\text {ig }}=3 t_{\text {pre }}$ for AMP.

The contributions of heat transfer and oxidation on ANP and AMP ignition were also examined by their normalized ratios in each stage, as shown in Fig. 9. It is seen that the contribution of heat conduction accounts for primary proportion during the overall stages. The proportion of heat radiation raises with increasing particle size, especially for $D_{\mathrm{p}}>100 \mu \mathrm{m}$. Hence the influence of radiation heat transfer cannot be neglected in modeling AMP ignition and combustion.

\subsection{Parametric study}

A parametric study was then conducted to obtain the key factors influencing $T_{\mathrm{ig}}$ and $t_{\mathrm{ig}}$ for both ANP and AMP, in which $T_{\mathrm{p} 0}=300 \mathrm{~K}$, $T_{\mathrm{a}}=2500 \mathrm{~K}$ and $P_{\mathrm{a}}=1 \mathrm{~atm}$ were maintained for $t_{\mathrm{ig}}$ prediction. The effects of oxide layer thickness and emissivity of particle were firstly examined (Fig. 10) from the viewpoint of particle properties. Three values of $\delta=3,5$ and $7 \mathrm{~nm}$ were selected according to available literatures $[23,68,69]$; and $\varepsilon$ was set as $0.1,0.2$ and $0.3[30,47]$. As shown in Fig. 10(a), the increase of $\delta$ raises $T_{\mathrm{ig}}$ (dash curves) and $t_{\mathrm{ig}}$ (solid curves) for ANP, which is consistent with the results of Ref. [20]. However, $\delta$ has little impact on $T_{\mathrm{ig}}$ and $t_{\mathrm{ig}}$ of AMP because the mass fraction of oxide layer accounts for only a small proportion of total particle mass. In contrast, $\varepsilon$ yields an important effect on the ignition of AMP as $D_{\mathrm{p}}>100 \mu \mathrm{m}$. The higher $\varepsilon$ results in a higher $T_{\mathrm{ig}}$ and a lower $t_{\mathrm{ig}}$.

From the viewpoint of environment, the influences of bulk gas velocity and oxygen concentration were then investigated (Fig. 11). As shown in Fig. 11(a), by increasing velocity from 0 to $100 \mathrm{~m} / \mathrm{s}$, there are no evident differences for both $T_{\mathrm{ig}}$ and $t_{\mathrm{ig}}$ as $D_{\mathrm{p}}<10 \mu \mathrm{m}$, i.e., $K n>0.1$. Hence, the bulk gas motion mainly influences the ignition in transition and continuum regimes, especially for $R e>5$. A higher $T_{a}$ is required to achieve the energy balance between heat transfer and oxidation during the fast oxidation stage, resulting in a higher $T_{\mathrm{ig}}$. Owing to enhancement of heat transfer, $t_{\mathrm{ig}}$ decreases with increasing $V_{\mathrm{s}}$ when $K n<0.1$.

Fig. 11(b) shows the effects of oxygen concentration. Both $T_{\mathrm{ig}}$ and $t_{\mathrm{ig}}$ decrease with increasing $Y_{\mathrm{O} 2}$. As $Y_{\mathrm{O} 2}$ increases, the heat release rate from oxidation of aluminum core enhances, leading to a relatively lower $T_{\mathrm{a}}$. However, $t_{\mathrm{ig}}$ decreases slightly, since $t_{\mathrm{ig}}$ is mainly determined by heat conduction and radiation (Fig. 9).

In summary, these results highlight that $\delta$ generally leads to increase of $T_{\mathrm{ig}}$ and $t_{\mathrm{ig}}$ for ANP ignition; in contrast the oxygen concentration reduces $T_{\mathrm{ig}}$ and $t_{\mathrm{ig}}$; the radiative emissivity plays an insignificant role as
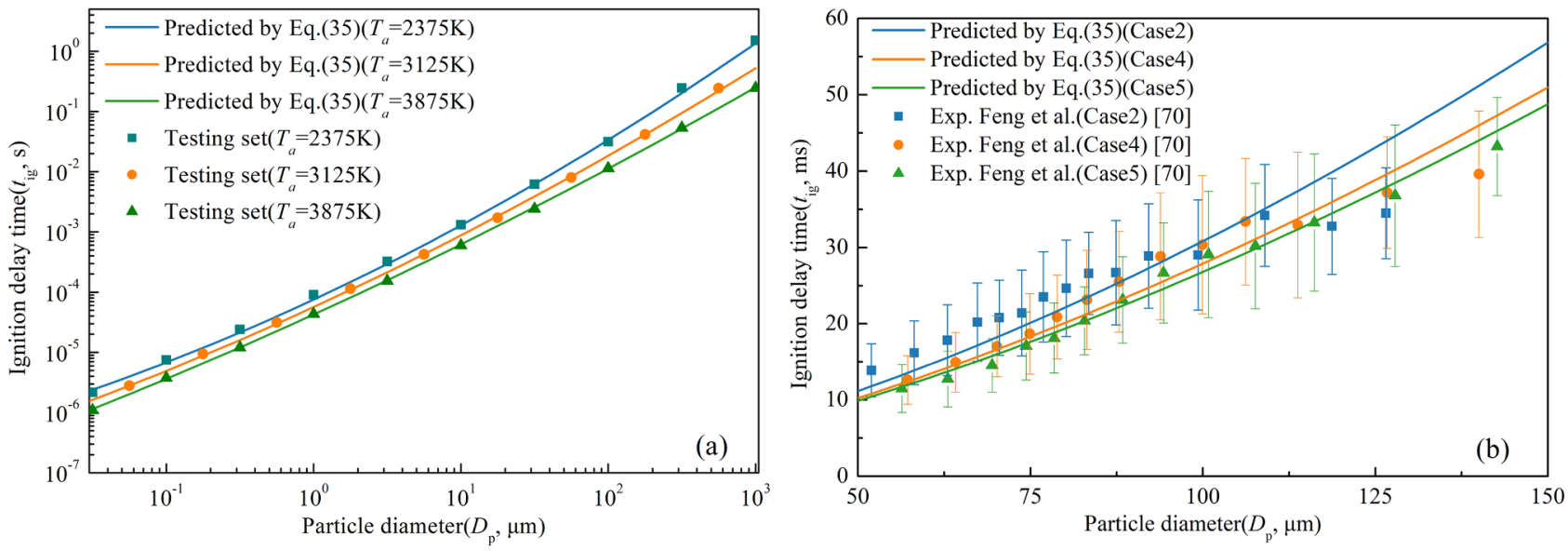

Fig. 12. Comparison of ignition delay times between prediction formula and theoretical model (a), as well as prediction and experiment data [70] (b). 
its value lying between 0.1 and 0.3 ; and the bulk velocity causes increase of $T_{\mathrm{ig}}$ and decrease of $t_{\mathrm{ig}}$ for AMP with $D_{\mathrm{p}}>100 \mu \mathrm{m}$.

On the other hand, it is reported that $\delta$ is generally in the range of 2-4 nm [30] for aluminum particle, and hence $\delta=3 \mathrm{~nm}$ can be adopted for further study. The value of TAC $=0.07$ also seems to be reasonable for ignition in air (Figs. 6 and 7). Then a prediction model for $t_{\text {ig }}$ was proposed through the machine learning method by considering two features $D_{\mathrm{p}}$ and $T_{\mathrm{a}}$. The training sets were calculated by the current model, covering a series of $D_{\mathrm{p}}(0.03-1000 \mu \mathrm{m})$ and $T_{\mathrm{a}}$ $(2250-4000 \mathrm{~K})$. The trained prediction model is described in Eq. (35), and the specific values of $a_{\mathrm{ij}}$ are listed in Table 3 .

$\log t_{\mathrm{ig}}=\sum_{\mathrm{i}=0}^{2} \sum_{\mathrm{j}=0}^{2} a_{\mathrm{ij}}\left(\log D_{\mathrm{p}}\right)^{\mathrm{i}} T_{\mathrm{a}}^{\mathrm{j}}$

In order to verify the formula, testing $t_{\text {ig }}$ different from the training sets was computed by the theoretical model. The values predicted by Eq. (35) and testing sets are compared in Fig. 12(a), in which the Pearson correlation coefficient is above 0.92 , indicating that the prediction formula can yield an accurate result. Furthermore, $t_{\mathrm{ig}}$ measured in the post flame of methane-air-oxygen in Ref. [70] was also employed to validate the prediction formula. And the cases 2, 4 and 5 with initial ambient temperatures around $T_{\mathrm{a}}=2475,2595$ and $2645 \mathrm{~K}$ [70] respectively were chosen to compare with the predicted results, as shown in Fig. 12(b). Although the ambient components are different from the present model to some extent, it may be used as a reference to validate the prediction formula because the ignition delay time decreased slightly as carbon dioxide was substituted for partial oxygen according to experiments of AMP ignition and combustion [71]. Both comparisons reveal that the formula is able to appropriately predict $t_{\mathrm{ig}}$ over a wide range of $D_{\mathrm{p}}$ and $T_{\mathrm{a}}$.

\section{Conclusions}

The present study proposes a theoretical model to predict the ignition characteristics of both nano/micro aluminum particles burning in oxygen atmosphere. The heat transfer model covering free-molecular to continuum regimes is firstly developed and validated by direct simulation Monte Carlo and CFD simulations, yielding an accurate method to calculate the heat conduction or convection of aluminum particles from nano to micro-size. This model is also applicable to the heat transfer modeling of soot and other metal particles. A unified form of oxidation law is also proposed for particles with different sizes. Based on the validated model, the ignition temperature and ignition delay time have been determined, which show good agreements with experimental data. Two formulas have been established to conveniently and accurately capture the ignition temperature and ignition delay time for various sizes of aluminum particles, which have not yet been proposed previously.

It is found that the heat conduction plays the dominant role in particle ignition and the influence of heat radiation strengthens as particle size increase to micro-size. In addition, the ignition of microparticle is sensitive to flow velocity and oxygen concentration, particularly for that with $D_{\mathrm{p}}>100 \mu \mathrm{m}$. In contrast, the ignition temperature and ignition delay time for the aluminum nanoparticle increase with oxide layer thickness, and they are rarely affected by radiation emissivity and bulk flow velocity. This study provides a fundamental understanding on the ignition of aluminum particles in a variety of sizes and a guideline to prompt ignition.

\section{CRediT authorship contribution statement}

Xiangrui Zou: Investigation, Methodology, Software, Validation, Writing - original draft. Ningfei Wang: Conceptualization, Supervision, Funding acquisition. Lijuan Liao: Conceptualization, Investigation, Validation. Qingzhao Chu: Software, Validation. Baolu Shi:
Methodology, Investigation, Project administration, Funding acquisition, Writing - review \& editing.

\section{Declaration of Competing Interest}

The authors declare that they have no known competing financial interests or personal relationships that could have appeared to influence the work reported in this paper.

\section{Acknowledgment}

This work was supported by the Domain Foundation of Equipment Advance Research of 13th Five-year Plan (Grant No. 61407200201) and National Natural Science Foundation of China (Grant No. 11672314, No. 51676016 and No. 11972087).

\section{References}

[1] Sundaram DS, Yang V, Yetter RA. Metal-based nanoenergetic materials: Synthesis, properties, and applications. Prog Energy Combust Sci 2017;61:293-365.

[2] Totten GE, MacKenzie DS. Handbook of aluminum: vol. 1: physical metallurgy and processes. CRC Press; 2003.

[3] King MK. Aluminum combustion in a solid rocket motor environment. Proc Combust Inst 2009;32:2107-14.

[4] Stiel LI. Study of detonation and cylinder velocities for aluminized explosives. AIP Conf. Proc., vol. 845, Baltimore, Maryland (USA): AIP; 2006, p. 475-8.

[5] Yetter RA, Risha GA, Son SF. Metal particle combustion and nanotechnology. Proc Combust Inst 2009;32:1819-38.

[6] Bergthorson JM. Recyclable metal fuels for clean and compact zero-carbon power. Prog Energy Combust Sci 2018;68:169-96.

[7] Gumus S, Ozcan H, Ozbey M, Topaloglu B. Aluminum oxide and copper oxide nanodiesel fuel properties and usage in a compression ignition engine. Fuel 2016;163:80-7.

[8] Miller TF, Walter JL, Kiely DH. A next-generation AUV energy system based on aluminum-seawater combustion. Proc. 2002 Workshop Auton. Underw. Veh. 2002, San Antonio, TX, USA: IEEE; 2002, p. 111-9.

[9] Babuk VA, Vasilyev VA. Model of aluminum agglomerate evolution in combustion products of solid rocket propellant. J Propuls Power 2002;18:814-23.

[10] Kong C, Yu D, Yao Q, Li S. Morphological changes of nano-Al agglomerates during reaction and its effect on combustion. Combust Flame 2016;165:11-20.

[11] Friedman R, Macek A. Ignition and combustion of aluminium particles in hot ambient gases. Combust Flame 1962;6:9-19.

[12] Gurevich MA, Lapkina KI, Ozerov ES. Ignition limits of aluminum particles. Combust Explos Shock Waves 1970;6:154-7.

[13] Merzhanov AG. Thermal theory of metal particle ignition. AIAA J 1975;13:209-14.

[14] Merzhanov AG, Grigorjev YuM, Ga'lchenko Yu A. Aluminium ignition. Combust Flame 1977;29:1-14.

[15] Roberts TA, Burton RL, Krier H. Ignition and combustion of aluminum/magnesium alloy particles in $\mathrm{O}_{2}$ at high pressures. Combust Flame 1993;92:125-43.

[16] Fedorov AV, Kharlamova YV. Ignition of an aluminum particle. Combust Explos Shock Waves 2003;39:544-7.

[17] Trunov MA, Schoenitz M, Dreizin EL. Effect of polymorphic phase transformations in alumina layer on ignition of aluminium particles. Combust Theory Model 2006:10:603-23.

[18] Liu F, Daun KJ, Snelling DR, Smallwood GJ. Heat conduction from a spherical nanoparticle: status of modeling heat conduction in laser-induced incandescence. Appl Phys B 2006;83:355-82.

[19] Allen D, Krier H, Glumac N. Heat transfer effects in nano-aluminum combustion at high temperatures. Combust Flame 2014;161:295-302.

[20] Chowdhury S, Sullivan K, Piekiel N, Zhou L, Zachariah MR. Diffusive vs explosive reaction at the nanoscale. J Phys Chem C 2010;114:9191-5.

[21] Zhang S, Dreizin EL. Reaction interface for heterogeneous oxidation of aluminum powders. J Phys Chem C 2013;117:14025-31.

[22] Noor F, Zhang H, Korakianitis T, Wen D. Oxidation and ignition of aluminum nanomaterials. PCCP 2013;15:20176-88.

[23] Kong C, Yu D, Li S, Yao Q. Mechanism and modelling of aluminium nanoparticle oxidation coupled with crystallisation of amorphous $\mathrm{Al}_{2} \mathrm{O}_{3}$ shell. Combust Theor Model 2016;20:296-312.

[24] Rai A, Park K, Zhou L, Zachariah MR. Understanding the mechanism of aluminium nanoparticle oxidation. Combust Theor Model 2006;10:843-59.

[25] Chu Q, Shi B, Liao L, Luo KH, Wang N, Huang C. Ignition and oxidation of core-shell $\mathrm{Al} / \mathrm{Al}_{2} \mathrm{O}_{3}$ nanoparticles in an oxygen atmosphere: insights from molecular dynamics simulation. J Phys Chem C 2018;122:29620-7.

[26] Levitas VI, Asay BW, Son SF, Pantoya M. Melt dispersion mechanism for fast reaction of nanothermites. Appl Phys Lett 2006;89:071909.

[27] Levitas VI, Pantoya ML, Dean S. Melt dispersion mechanism for fast reaction of aluminum nano- and micron-scale particles: Flame propagation and SEM studies. Combust Flame 2014;161:1668-77.

[28] Li Y, Kalia RK, Nakano A, Vashishta P. Size effect on the oxidation of aluminum nanoparticle: Multimillion-atom reactive molecular dynamics simulations. J Appl 
Phys 2013;11.

[29] Mohan S, Trunov MA, Dreizin EL. Heating and ignition of metal particles in the transition heat transfer regime. J Heat Transf 2008;130:104505.

[30] Sundaram DS, Puri P, Yang V. A general theory of ignition and combustion of nanoand micron-sized aluminum particles. Combust Flame 2016;169:94-109.

[31] Ermoline A. Thermal theory of aluminum particle ignition in continuum, free-molecular, and transition heat transfer regimes. J Appl Phys 2018;124:054301.

[32] Langmuir I. The dissociation of hydrogen into atoms. [PART II.] Calculation of the degree of dissociation and the heat of formation. J Am Chem Soc 1915;37:417-58.

[33] Fuchs N. Growth and evaporation of drops in gaseous media. London: Pergamon Press; 1959.

[34] Bird GA, Brady J. Molecular gas dynamics and the direct simulation of gas flows. Oxford: Clarendon Press; 1994. p. 5.

[35] Filippov AV, Rosner DE. Energy transfer between an aerosol particle and gas at high temperature ratios in the Knudsen transition regime. Int J Heat Mass Transf 2000;43:127-38.

[36] Wang M. Similarity of ideal gas flow at different scales. Sci China Ser E: Technol Sci 2003;46:661.

[37] Mao Q, van Duin ACT, Luo KH. Investigation of methane oxidation by palladiumbased catalyst via ReaxFF Molecular Dynamics simulation. Proc Combust Inst 2017;36:4339-46.

[38] Zhang YR, van Duin ACT, Luo KH. Investigation of ethanol oxidation over aluminum nanoparticle using ReaxFF molecular dynamics simulation. Fuel 2018;234:94-100.

[39] Kong C, Yao Q, Yu D, Li S. Combustion characteristics of well-dispersed aluminum nanoparticle streams in post flame environment. Proc Combust Inst 2015;35:2479-86.

[40] Fuchs NA. On the stationary charge distribution on aerosol particles in a bipolar ionic atmosphere. Geofis Pura E Appl 1963;56:185-93.

[41] Wright P. On the discontinuity involved in diffusion across an interface (the $\Delta$ of Fuchs). Discuss Faraday Soc 1960;30:100-12.

[42] Whitaker S. Forced convection heat transfer correlations for flow in pipes, past flat plates, single cylinders, single spheres, and for flow in packed beds and tube bundles. AIChE J 1972;18:361-71.

[43] Oppenheim AK. Generalized theory of convective heat transfer in a free-molecule flow. J Aeronaut Sci 1953;20:49-58.

[44] Sauer FM. Convective heat transfer from spheres in a free-molecule flow. J Aeronaut Sci 1951;18:353-4.

[45] Springer GS. Heat transfer in rarefied gases. Adv. Heat Transf., vol. 7, Elsevier; 1971, p. 163-218.

[46] Sherman FS. A survey of experimental results and methods for the transition regime of rarefied gas dynamics. Rarefied Gas Dyn. Proc Third Int. Symp. Rarefied Gas Dyn. Paris Fr. 1962, 1962, p. 228-260.

[47] Reynolds P. Spectral emissivity of $99.7 \%$ aluminium between 200 and $540^{\circ} \mathrm{C}$. Br. J Appl Phys 1961;12:111.

[48] Lide DR. CRC handbook of chemistry and physics. CRC Press; 2004.

[49] Stull DR, Prophet H. JANAF thermochemical tables. National Standard Reference Data System; 1971.

[50] Burcat A, Ruscic B. others. Third millenium ideal gas and condensed phase thermochemical database for combustion (with update from active thermochemical tables). Argonne, IL (United States): Argonne National Lab. (ANL); 2005.
[51] Goodwin DG, Moffat HK, Speth RL. Cantera: An object-oriented software toolkit for chemical kinetics, thermodynamics, and transport processes. Caltech Pasadena CA 2009.

[52] Chen SHP, Saxena SC. Thermal conductivity of argon in the temperature range 350-2500 K. Mol Phys 1975;29:455-66.

[53] Jain PC, Saxena SC. Thermal conductivity and effective diffusion coefficient for vibrational energy: oxygen (400-1600 K). Mol Phys 1977;33:133-8.

[54] Faubert FM, Springer GS. Measurement of the thermal conductivity of argon, krypton, and nitrogen in the range 800-2000K. J Chem Phys 1972;57:2333-40.

[55] Mikami H, Endo Y, Takashima Y. Heat transfer from a sphere to rarefied gas mixtures. Int J Heat Mass Transf 1966;9:1435-48.

[56] Maheshwari A, Chhabra R, Biswas G. Effect of blockage on drag and heat transfer from a single sphere and an in-line array of three spheres. Powder Technol 2006;168:74-83.

[57] White C, Borg MK, Scanlon TJ, Longshaw SM, John B, Emerson DR, et al. dsmcFoam +: An OpenFOAM based direct simulation Monte Carlo solver. Comput Phys Commun 2018;224:22-43.

[58] Scanlon TJ, Roohi E, White C, Darbandi M, Reese JM. An open source, parallel DSMC code for rarefied gas flows in arbitrary geometries. Comput Fluids 2010;39:2078-89.

[59] Seabold S, Perktold J. Statsmodels: Econometric and statistical modeling with python. Proc. 9th Python Sci. Conf., vol. 57, Scipy; 2010, p. 61.

[60] Mane T. Energy accommodation under non-equilibrium conditions for aluminuminert gas systems. Surf Sci 2018;677:135-48.

[61] Allen D, Krier H, Glumac N. Nano-alumina accommodation coefficient measurement using time-resolved laser-induced incandescence. J Heat Transf 2016;138:112401.

[62] Altman I. High-temperature estimation of energy accommodation coefficient of gas molecules on the surface. J Phys Stud 1999;3:456-7.

[63] Parr T, Johnson C, Hanson-Parr D, Higa K. Wilson K. Evaluation of advanced fuels for underwater propulsion. 39 ${ }^{\text {th }}$. JANNAF Combust. Subcomm. Meet. 2003.

[64] Bulian C, Kerr T, Puszynski J. Ignition studies of aluminum and metal oxide nanopowders. $31^{\text {st }}$ Proc Int Pyrotech Semin. 2004. p. 327-38.

[65] Fedoseev V. Burning of magnesium and aluminum particles in various media ( $\mathrm{Mg}$ and $\mathrm{Al}$ particles burning in air, water vapor, $\mathrm{Cl}$ and nitrous oxide). Fiz Aerodispersnykh Sist 1970:61-72.

[66] Brossard C, Ulas A, Yeh C, Kuo K. Ignition and combustion of isolated aluminum particles in the post-flame region of a flat-flame burner. Int. Colloq. Dyn. Explos. React. Syst. 16th Krakow Pol. Aug 3-8 1997 ONERA TP; 1997.

[67] Ermakov VA, Razdobreev AA, Skorik AI, Pozdeev VV, Smolyakov SS. Temperature of aluminum particles at the time of ignition and combustion. Combust Explos Shock Waves 1982;18:256-7.

[68] Coulet MV, Rufino B, Esposito PH, Neisius T, Isnard O, Denoyel R. Oxidation mechanism of aluminum nanopowders. J Phys Chem C 2015;119:25063-70.

[69] Gan Y, Qiao L. Combustion characteristics of fuel droplets with addition of nano and micron-sized aluminum particles. Combust Flame 2011;158:354-68.

[70] Feng Y, Xia Z, Huang L, Ma L. Effect of ambient temperature on the ignition and combustion process of single aluminium particles. Energy 2018;162:618-29.

[71] Servaites J, Krier H, Melcher JC, Burton RL. Ignition and combustion of aluminum particles in shocked $\mathrm{H}_{2} \mathrm{O} / \mathrm{O}_{2} / \mathrm{Ar}$ and $\mathrm{CO}_{2} / \mathrm{O}_{2} / \mathrm{Ar}$ mixtures. Combust Flame 2001;125:1040-54. 